\title{
Need to establish a new adolescent suicide prevention programme in South Korea
}

\author{
Jiacheng Liu
}

\begin{abstract}
Adolescent suicide is the leading cause of death among South Korean (Korean) youth. Despite great efforts being made towards suicide prevention in Korea, the suicide rate has not decreased significantly. There is an urgent need for a new adolescent suicide prevention strategy. This paper describes the seriousness of the issue of adolescent suicide in Korea, evaluates its current management by the SWOT analysis (strengths, weaknesses, opportunities and threats) and further recommends a new suicide prevention programme that integrates national/ social involvement (State Suicide Intervention Committee, suicide posts' monitoring, parental divorce information sharing and Adolescence Mental Health Promotion Foundation), schoolbased programmes (continuous monitoring system, psychology consultation team and mental health educational curricula) and familybased programmes (parental education and family-school communication). In addition, genetic analysis, biochemical tests and psychological disease registration are the indispensable elements that aid in suicidal behaviour prevention and prediction.
\end{abstract}

\section{INTRODUCTION TO KOREAN ADOLESCENT SUICIDE}

Suicide is the second leading cause of death among the youth worldwide. ${ }^{1}$ Nearly 3.4 million adolescents (aged 15-19 years) across the globe have suicidal ideation, with half of them attempting suicide. ${ }^{2}$ In Korea, the suicide rate was ranked the fourth in the world in $2018^{3}$ with $7.2 / 100000$ young people committing suicide, ${ }^{4}$ and the number of suicides among adolescents aged $15-18$ years is four times than that of adolescents aged 12-14 years according to data from the National Statistical Office of Korea. ${ }^{5}$ Korean adolescents seem to be at a risk of having suicide ideation or attempting suicide. In a recent study that used a nationwide data

Melbourne School of Population \& Global Health, Division of Medicine, Dentistry and Health Sciences, The University of Melbourne, Melbourne, Victoria, Australia

Correspondence to Jiacheng Liu; jiachengl5@student.unimelb.edu.au set of Korea Youth Risk Behavior Web-based Survey (KYRBWS), it was revealed that $12.4 \%(7443 / 59984)$ of middle and high school students had a history of suicidal ideation/ attempt. ${ }^{6}$ What is worse, only $11.1 \%$ to $21.6 \%$ of the adolescents aged 15 years or older with suicidal ideation or attempt are receiving psychiatric treatment. ${ }^{7}$

The causes of suicide in Korean youth are complicated. Moreover, $34.3 \%$ of suicides are associated with family problems, ${ }^{8}$ including family history of suicide/mental disorders and low family support ${ }^{9} ; 17.6 \%$ are related to students' own psychiatric disorders, such as depression, and another $12 \%$ are due to the academic burden at school. ${ }^{810}$ Other factors, including alcohol/substance abuse, $^{9} 11$ peer bullying and social stigma regarding a mental illness, ${ }^{10}$ are all associated with suicide attempts by Korean adolescents.

Considering the gravity of the issue of suicide in Korean youth, the Korean Ministry of Education introduced a mandatory policy in 2015 that required a suicide report should be submitted by the school within 1 week of a student committing suicide. ${ }^{8}$

\section{SWOT ANALYSIS OF CURRENT SUICIDE MANAGEMENT}

To perform an in-depth assessment of the current Korean suicide prevention strategies, a SWOT (strengths, weaknesses, opportunities and threats) analysis is used. SWOT is a widely used qualitative method in a variety of fields, including business, medicine, public health, education, politics and so on. Through a thorough and structured analysis of the available data relating to a topic of interest, all the intrinsic and extrinsic factors, even the mechanism involved in the occurrence, progression and outcome of a focused event, are explored, which enables the stakeholders to have a comprehensive insight and, most importantly, to propose a far-sighted and practical strategy to deal with the issues in a more efficient way. ${ }^{12-14}$ In the medical and public health field, although SWOT analysis is not a prospective, double-blind clinical trial, which can provide the highest level of evidence, it is still an important technique to alter and improve the disease prevention and treatment standards ${ }^{15}$ and is helpful for future clinical and basic research. ${ }^{16}$

\section{Strengths}

The Korean government provides powerful leadership on suicide prevention. A Five Year Plan for National Mental Health was released in 1998, and it is updated every 5 years. ${ }^{17}$ In 2004, media guidance was introduced, stressing the importance of providing responsible reports related to suicides, and amendment 3.0 was announced in $2018 .{ }^{18}$ In addition, the Korea Suicide Prevention Centre (KSPC), which is supported directly by the government, was established in 2011 with the primary tasks of preventing high-risk suicides, improving media guidelines, building internet monitoring system and so on. ${ }^{18}$ The Korean Ministry of Education also held six vital prevention projects for the young, including evidence-based prevention strategies, de-stigmatised social mental health campaigns, early suicide detection systems, liaisons between the medical support system and psychologists, skills training for students and teachers and prevention education for adolescents. 8

In addition, non-governmental organisations (NGOs) are actively involved in suicide prevention programmes. The Korean Association for Suicide Protection launched several programmes in 2011, such as 'Livingworks' and its branches 'ASIST' and 'safeTALK', to train mental health professionals and encourage young people with mental disorders to communicate openly with others. ${ }^{19}$ By the end of 2017, 7342 help providers had joined the 
'ASIST' training programme, and 9102 adolescents had taken part in 'safeTALK'.20

Other efforts are being made to prevent suicides in Korea. KSPC developed an internet monitoring team to delete harmful online posts. According to the team, 3123 posts regarding suicide encouragement and recruitment are deleted on a normal day. ${ }^{18}$ The National Institute of Mental Health and the Division of Mental Health Services are devoted to mental health research exploring the aetiology of suicides in Korean adolescents and prevention strategies, ${ }^{10} 17$ the link between mental disorders and a person's genetic background, ${ }^{21}$ and so on. It is clear that the Korean government and NGOs have paid close attention to youth suicide and have adopted several strategies.

\section{Weaknesses}

Although numerous efforts have been made, a significant decline in the suicide rate has not yet been observed. $^{22}$ The primary reason is the social stigma towards mental illness embedded in Korean culture. On the one hand, most Korean people think it is shameful to admit that they have mental health problems. Seventy percent of students with suicidal ideation do not display their problematic behaviours at school. ${ }^{8}$ Thus, it is hard for the teachers to observe any behavioural abnormalities in these students. On the other hand, even if the Ministry of Education introduced projects to intervene and prevent suicide issues, schools prefer to conceal the suicidal incidents rather than seek help from the governmental institutions. ${ }^{23}$ This is due to the fact that schools are reluctant to undertake the responsibilities and avoid being stigmatised given that the public often holds the school responsible for student suicide. ${ }^{23}$

Another weakness is insufficient financial investment. The Korean government doubled the budget for mental care-related fields from 18 million US \$ in 2010 to 43 million US \$ in $2014,{ }^{17}$ but it still only accounted for less than $3 \%$ of total healthcare expenditures, much lower than WHO's recommendation $(15 \%-50 \%))^{17}$

\section{Opportunities}

The great developments in information and computer technologies, especially the advances in artificial intelligence and deep learning, provide the opportunities to recognise and screen the students with suicidal ideation at an early stage, including those who have been previously received a diagnosis of psychiatric disorders. As acknowledged by teachers, the information provided in their suicide reports may be biased or incomplete. ${ }^{8}$ If closed-circuit televisions (CCTVs) could be installed in every school covering every corner, detailed dynamic information on the students who committed suicides in the school could be traced. By analysing and comparing their behaviour 1 week or 1 month before the incident, some questionable and common behaviours might be recognised, which in turn could help implement suicide prevention training programmes for teachers that would enable them to notice such behaviours in the future.

Furthermore, modern internet surveillance technologies can assist the KSPC's internet monitoring team to extend their job from simply deleting harmful suicide posts to identifying who posts this information online, which is extremely helpful in offering timely help and saving lives.

Moreover, with the development of novel tools for analysing the genetics of psychiatric disorders, the precise molecular mechanism responsible for the occurrence of mental diseases and suicidal behaviours could be unravelled, and the link between disease genotypes and phenotypes could be established. ${ }^{24}$ It is highly likely that if a nationwide database with clinical information, self-report and teacherreport questionnaires, CCTV records and blood samples could be established, the interplay between the genetics of psychiatric diseases, social factors and suicide behaviour could be unravelled. ${ }^{25}$

\section{Threats}

The biggest threat of suicide in Korea comes from the lack of treatment. Only $15 \%-23 \%$ of individuals with mental disorders receive treatment, which is far less than the $44 \%$ treatment rate in western countries. ${ }^{17}$ Another threat comes from the internet. Currently, one can easily post suicidal encouragement text and video online anonymously, ${ }^{8} 18$ which has immeasurably vicious mental consequences, especially for youngsters. Other suicide-inducing factors, such as online game addiction ${ }^{8}$ and loneliness, which are caused by poor social/family relationships, ${ }^{38}$ parental divorce $^{8}$ and social stigma towards mental diseases, ${ }^{26} 27$ have also been identified. These diverse and complex risk factors increase the difficulty of adolescent suicide prevention in Korea.

\section{RECOMMENDATIONS FOR CURRENT SUICIDE PREVENTION STRATEGIES}

According to the aforementioned SWOT analysis, there is a need to update the current suicide prevention strategies in Korea and establish an integrated framework at the administration level and healthcare level with factors related to nation/ society, schools, families, genetic architecture, biochemical markers and psychiatric disease registration (figure 1). Several specific measures could be taken as suggested in the figure.

\section{Suicide prevention strategies should} have a top-level design from central government to research institutes and communities

National/social level

\section{Setting up the State Suicide Intervention} Committee

Similar to the coronavirus disease 2019 (COVID-19) pandemic where the medical and public health staff alone cannot be relied on for controlling the pandemic, there is an urgent need for the central government in each country to take bold, innovative and courageous actions that are aimed at suicide prevention in adolescents. ${ }^{28} 29$ The current Korean mental health service 
delivery system is led by the Ministry of Health and Welfare. ${ }^{17}$ More powerful leadership is needed to gather all the necessary resources and strengths to prevent adolescent suicides. One suggestion is that the Korean government establishes a State Suicide Intervention Committee (SSIC) that is directly led by the state premier. This committee should comprise highranking officials from the Ministry of Education, Finance, Health, Justice and so on, in co-operation with top experts from the areas of computer science, internet monitoring, ethical issues and social networking services (SNS) as well as NGOs. Furthermore, the SSIC should grant permission to collect all the necessary data and develop/evaluate/adjust its suicide prevention strategies.

It should be emphasised that powerful leadership provided by the government on national adolescent suicide prevention relies on the mental health law legislation, ${ }^{30}$ with the aim to screen students who are at risk of harming themselves and others, provide sufficient financial budget to expand and improve the mental health services, as well as to conduct highquality research in suicide prevention. SSIC is also responsible for promoting the development and amendment of mental health management law and bills.

\section{Monitoring online suicide posts to identify adolescents at risk of suicide}

The importance of monitoring and analysing suicide-related posts on the internet is undeniable. The high viewership of teenage suicide on social media has become a great concern, but at the same time, it provides the chance to protect the young people expressing their intent to self-harm and suicidal thoughts on the internet. ${ }^{31-33}$ It was recently reported that by analysing the online posts to identify those suggestive of suicide thoughts and behaviour, individuals at risk of suicide could be contacted and managed by trained counsellors. ${ }^{34}$ SNS and KSPC should co-operate to upgrade and set up a nationwide online suicide information monitoring system. The primary functions of this system are

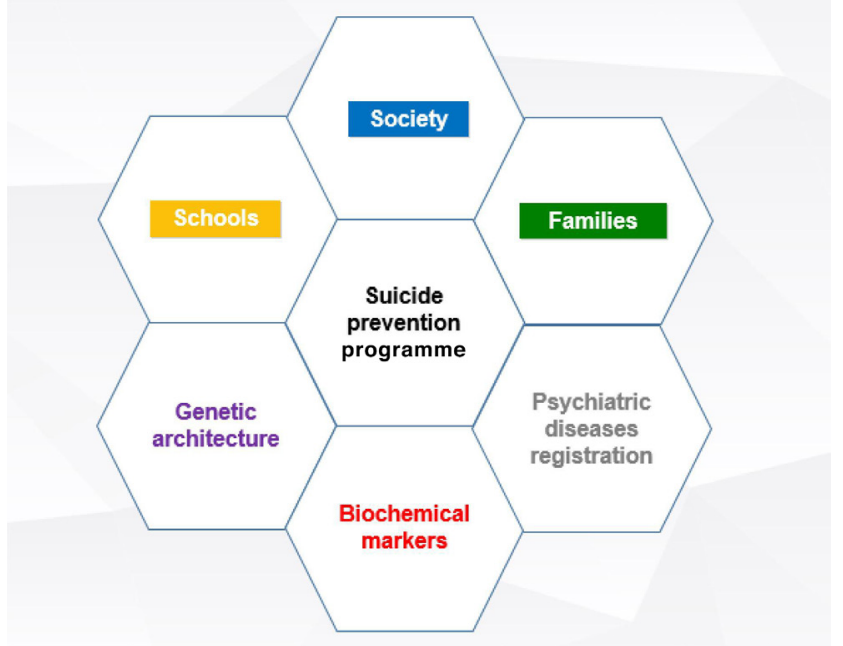

Figure 1 Integrated programme to prevent suicides (in Korean adolescents).

threefold: (1) identifying individuals who are attempting suicide or instigating suicidal action through 24/7 internet surveillance; (2) taking urgent measures to stop it through co-operation with local government; (3) retrospectively obtaining and analysing all the information in social media and on websites posted by young people who have just committed suicide. These data are important for suicide prediction and prevention.

\section{Sharing parental divorce information}

Parental divorce is commonly seen in suicide cases in female adolescents. ${ }^{8}$ SSIC should make a rule that the parents' divorce information be shared with the local Education Bureau, with the latter informing schools to pay more attention to these students. The school should communicate with the students' parents, asking them and their child(ren) to use 24/7 hotline whenever they need help. Furthermore, SSIC should make comprehensive and consistent efforts to restrict the access to lethal means, such as control of analgesics, install platform physical barriers in metro stations and so on. ${ }^{35} 36$

\section{Setting up the Adolescence Mental Health Promotion Foundation}

The current financial resources for suicide prevention primarily come from the Korean central government, ${ }^{17}$ and they are not sufficient. This paper suggests setting up the Adolescence Mental Health Promotion Foundation under the SSIC. Its primary functions are (1) seeking and accepting financial support from big enterprises, financial groups and personal donations; and (2) conducting mental health education programmes for adolescents. Adolescence is a special period characterised by great mental and physical changes. The lack of ability to regulate emotions, social influence and sensation-seeking behaviour are the major contributing factors for adolescents committing self-injuries. ${ }^{37}$ Thus, mental health education programmes should address adolescent physical and mental development. A recent study conducted in Korean adolescents found an association between suicide and the number of psychiatrists and the availability of community health services $^{38}$; this finding further illustrates the importance and necessity to provide more psychological care to adolescents. The following actions can be taken: (1) a mental health education programme should be conducted online and offline on the WHO suicide day (10 September), and periodically (every 3 months) to introduce knowledge of mental health, the concept of cherishing life and how to deal with unhealthy moods; (2) setting up a 24/7 hotline with the telephone number 910 to provide consultations and help for adolescents experiencing psychological distress or having difficulties coping with challenging life events.

The responsibilities of the Adolescence Mental Health Promotion 
Foundation would be especially crucial in emergency conditions, such as during the pandemic outbreak of COVID-19 around the world including Asian countries such as Korea. ${ }^{39}$ People living in the affected areas have already suffered from a variety of mental problems, such as fear, hopelessness, loneliness, guilt, discrimination, racist attacks and even suicide. ${ }^{40-42}$ Special physiological care should be given to adolescents and students. ${ }^{4344}$ In Korea, schools are closed owing to COVID19, and the Ministry of Education has decided to extend the school closures. ${ }^{45}$ Thus, attention should be paid to the psychological changes in the local students and particularly those international students living alone because of lock-downs, ${ }^{42}$ instructing them to avoid untruthful information and to provide more online physiological consultations with any available methods, such as social media-based approaches and necessary personal protection materials, such as masks and so on. ${ }^{40}{ }^{44}$ All these supports can be delivered by the Foundation.

\section{School-based programmes CCTV installation}

The retrospective suicide report submitted by teachers may contain subjective bias and miss some key information. ${ }^{8}$ To obtain more objective and realistic information, installing CCTVs in all the schools and making full use of the campus surveillance system that runs day and night is a solution. ${ }^{46}$ The benefits of this strategy will show in the long term. It was shown that station staff training programmes and CCTV analysis of particular behavioural themes related to suicide potential in stations could both contribute to railway station suicide intervention and prevention efforts. ${ }^{47}$ In a Korean adolescent suicide case, if a student takes his/her own life, CCTV recordings of his/her previous 1 week/month, along with the teacher's report, should be submitted to the SSIC for detailed analysis using artificial intelligence techniques to identify any subtle or obviously abnormal behaviours suggestive of suicidal ideation. ${ }^{47}$ Thereafter, these abnormal behaviours will be introduced to teachers and the public via training programmes and social media to alert the public to notice these behaviours and adopt necessary intervening measures. This strategy will enable them to stop another student from committing suicide and reduce the suicide rate in the long term.

\section{Psychology consultation team and mental health educational curricula}

According to an investigation performed in 2402 adolescents in Shanghai, it was revealed that $21.7 \%$ of the students experienced nonsuicidal self-injury behaviour largely because of deficient emotional regulation and social influence. ${ }^{37}$ Thus, it is necessary to set up or improve schoolwide awareness of mental health and suicide and facilitate the access to mental health services. The schools should establish a psychology consultation team consisting of student and teacher representatives, ethical professionals, lawyers and psychologists, with the right to directly report to local government and make a quick referral in case of an emergency. They should hold routine meetings every 3 months or urgent meetings whenever necessary. The meeting topics are student behaviours, moods and thoughts in the family and in schools; the potential effects of a most recent social, family or school event(s) on the students' mental health; and ways to deal with stress.

A previous study has reported that even medical students are reluctant to disclose their mental health problems. ${ }^{48}$ Thus, educational programmes, curricula and various school activities should be presented to increase student knowledge about mental health problems and literacy, their suicide risk awareness, the capacity to lessen academic pressure, and ways to improve moods and a sense of well-being, and, most importantly, to encourage the students having suicidal ideation to actively seek help. The students also need to be instructed what they should do when they find a classmate with suicidal ideation. A psychology consultation team should conduct anonymous and voluntary surveys regularly to enable the students to express their feedback about the current lessons/curriculum arrangement and suggestions about the prospective programmes on unmentioned aspects. For example, according to an online questionnaire survey through campus network conducted in 466 undergraduate college students in China, some unique behavioural features suggestive of depression were identified. $^{46}$ The results of these surveys should be discussed during the routine meetings of the psychology consultation team along with the need for further adjustments in lessons and curriculum. The education programme should also focus on the gatekeepers in school, including school staff members and school counsellors, to improve their ability to identify and help at-risk students.

\section{Family-based programmes}

The Korean society places strong emphasis on family relations; on the one hand, this cultural feature of family being at the core is good for the prevention of suicide, but on the other hand, this may have a devastating effect when the close-knit relationship within the family members is disturbed. For example, experiencing parental verbal or physical abuse will intensify the ideation of suicide in Korean adolescents. ${ }^{49}$ Confucianism is another characteristic feature of the Korean culture. Within the family, this likely translates to the boundless and excessive expectations from parents, which children must fulfil. Such an academic stress, also called 'education fever' within the family, is one of the causes of suicide in Korean adolescents. ${ }^{49}$ In addition, owing to the Korean cultural and social stigma, it is shameful to admit having mental health problems. ${ }^{27}$ Thus, family-based programmes to educate parents not to put undue pressure on their children and to improve parents' mental health literacy and family support, especially in those families with a history of mental illnesses, are indispensable in suicide prevention in the young. ${ }^{8}$

These educational programmes containing psychological training should also be held by the school psychology consultation team to improve parental awareness about 
mental health, recognise potential suicidal behaviours in their child(ren), instruct the parents to communicate with their child(ren) about how they are feeling, provide information on how to support the child(ren) and teach them how to seek help from the school and society. These education programmes should also encourage parents to establish mutually trusting relationships with the school and to report their concerns or observations about their child(ren)'s mental health conditions to the school psychology consultation team. Because familyrelated issues are the leading cause of adolescent suicide, ${ }^{8}$ parents are strongly recommended to report their family conflicts.

\section{Upgrading the current suicide report} system to a new bio-information system In the era of evidenced-based medicine and precision medicine, a systemic biology approach is crucially needed for disease prevention and treatment. ${ }^{50}$ Although several suicide prevention activities or strategies have been implemented, strategies proven effective in reducing suicide rates, such as early intervention for youth with mental health disorders, are often not available. Only through a comprehensive and in-depth investigation on the genetic architecture, biomarkers and comorbidities, can the high-risk population at pre-diagnostic or prodromal or asymptomatic stages be targeted, ${ }^{51-55}$ and clinical patients can be classified ${ }^{56}$ and be treated individually. ${ }^{50} 57$

Currently, Korea has implemented a suicide report system with the information mainly provided by the teachers who have a suicidal student. Although the system is good, it needs to be improved substantially. The aetiology of suicides is multi-factorial involving genetic, biochemical abnormalities and mental disorders. Understanding the genetic architecture of suicidal behaviours and exploring its relationship with other biological traits to generate quantitative risk probability of suicide is extremely important for suicide prevention and is now technically feasible. ${ }^{58} 59$ For example, the most recent genome-wide association study confirmed the common genetic background of those who attempted suicide with different mental disorders, such as major depression, bipolar disorder and schizophrenia. ${ }^{60}$ Suicidal behaviour is aggregated within the family; the genetic transmission of suicide attempt has been recently confirmed in a large-scale case-control study consisting of 6024 cases of suicide attempt and 44240 controls with no record of a suicide attempt. ${ }^{61}$

In addition to the genetic background, peripheral and central inflammatory abnormalities are involved in the pathophysiology of suicidal behaviour. ${ }^{62}$ The changes of inflammatory cytokines, neurotransmitters and other biochemical markers such as serotonin, catecholamines, norepinephrine and dopamine with suicidal behaviours have been widely reported. ${ }^{62}{ }^{63}$ Although psychological status is also related to other diseases, such as cardiovascular diseases, diabetes and their complications, ${ }^{64-66}$ suicidal attempts are mostly reported in subjects with pre-existing mental illness. ${ }^{67}$ It is thus rational to upgrade the current suicide report system to a new bio-information system covering genetic, biochemical and psychological illness information. The functionalities of this new system are, but not limited to, data collection and analysis, monitoring and surveillance, prediction and prevention, and education and treatment.

\section{CHALLENGES}

The major challenges posed by this programme are its financial burden, shortage of professionals, ethical concerns and cultural barriers. First, the funding provided to the mental health sector within the overall healthcare system is very low (3\%) compared with WHO's suggestions $(15 \%-50 \%) .{ }^{17}$ Setting up a foundation may partly solve this problem.

Second, this programme requires the involvement of a large number of psychologists and general practitioners in the communities. Unfortunately, depression and other psychiatric disorders are under-recognised and undertreated in the primary care setting or general hospitals because of the lack of knowledge of physicians in the setting of primary care or general hospitals and thus failure to screen patients for depression. Therefore, improving physician knowledge of depression and suicide risk evaluation is a central component in suicide prevention. However, cultivating and training these professionals is time consuming. Whether the supply of these experienced experts could meet the demand is doubtful. However, $\mathrm{WHO}^{1}$ confirmed that the Secretariat will provide the necessary support for technology improvement and training programmes.

The third potential challenge pertains to ethical and privacy concerns. The ethical issues of privacy confidentiality in the implementation of prevention programme initiatives, such as sharing parental divorce information and the installation of CCTVs at schools, also should be taken into serious consideration. How to ensure that all the information collected from schools, family and psychological services, and blood samples is safe and does not aid discrimination is critical.

Fourth, cultural barriers prevent the public from talking about mental health issues openly and discussing family problems with others. The attitude towards mental health issues may need generations to convert.

Fifth, some suicide-related information is only accessible through exclusive networks using dedicated software, which is unlikely to find its users. ${ }^{68}$ Much work is needed to find these networks.

Finally, another set of evaluation and modification mechanisms is required to assess the efficacy and efficiency of all the measures already taken with specific targets and time table. The ultimate goal of the new system is a significant reduction in the suicide rate among Korean adolescents in 5-10 years.

\section{CONCLUSION}

The aetiologies of adolescent suicides are complex. The Korean government has already implemented a series of administrative and technical strategies to address suicides in the general 
population, including adolescents, which has led to some improvements. However, a great deal of work could be done to make further progress.

This paper proposes to adopt a new holistic programme with top-level design integrating administrative and technical forces to prevent suicide in adolescents. The Korean central government still plays a predominant role in this system. The stakeholders at nation/society, school and family levels work together to provide a healthy environment necessary for the development of mental health in adolescents. A nationwide bio-bank collecting genetic, biochemical, psychiatric disease and comorbidity information should be established to explore detailed mechanisms explaining suicidal ideation and behaviour and uncover novel biomarkers and genetic risk factors, which in turn will assist in developing a model suitable for suicide prediction, surveillance and education.

Acknowledgements The author thanks Michelle Williamson and Anna Ross from Melbourne School of Population \& Global Health at The University of Melbourne for their comments on this paper.

Contributors This paper was prepared and completed by JL alone.

Funding The author has not declared a specific grant for this research from any funding agency in the public, commercial or not-for-profit sectors.

Competing interests None declared.

Patient consent for publication Not required.

Provenance and peer review Not commissioned; externally peer reviewed.

\section{(อ) OPEN ACCESS}

Open access This is an open access article distributed in accordance with the Creative Commons Attribution Non Commercial (CC BY-NC 4.0) license, which permits others to distribute, remix, adapt, build upon this work non-commercially, and license their derivative works on different terms, provided the original work is properly cited, appropriate credit is given, any changes made indicated, and the use is non-commercial. See: http://creativecommons.org/ licenses/by-nc/4.0/.

(C) Author(s) (or their employer(s)) 2020. Re-use permitted under CC BY-NC. No commercial re-use. See rights and permissions. Published by BMJ.

Check for updates
To cite Liu J. General Psychiatry Epub ahead of print: [please include Day Month Year]. doi:10.1136/ gpsych-2020-100200

Received 18 January 2020

Revised 4 June 2020

Accepted 4 June 2020

General Psychiatry 2020;33:e100200.

doi:10.1136/gpsych-2020-100200

ORCID iD

Jiacheng Liu http://orcid.org/0000-0002-5663-0154

\section{REFERENCES}

1 World Health Organization. Mental Health Action Plan 2013-2020, 2013. Available: https://www.who.int/mental_health/action_ plan_2013/en/ [Accessed 6 Oct 2019].

2 Zalsman G. The neurobiological basis of suicide (Chapter 14). Boca Raton (FL): CRC Press/Taylor \& Francis, 2012.

3 World Population Review. Suicide rate by country 2019, 2019. Available: http://worl dpopulationreview.com/countries/suiciderate-by-country/ [Accessed 6 Dec 2019]

4 Lee K, Lee D, Hong HJ. Text mining analysis of teachers' reports on student suicide in South Korea. Eur Child Adolesc Psychiatry 2020;29:453-65.

5 Kim G-M, Kim J, Hyun MK, et al. Comparison of the risk factors of Korean adolescent suicide residing in high suicidal regions versus those in low suicidal regions. Psychiatr Danub 2019;31:397-404.

6 Jung JS, Park SJ, Kim EY, et al. Prediction models for high risk of suicide in Korean adolescents using machine learning techniques. PLoS One 2019;14:e0217639.

7 Park CHK, Lee JW, Lee SY, et al. The Korean cohort for the model predicting a suicide and suicide-related behavior: study rationale, methodology, and baseline sample characteristics of a long-term, large-scale, multi-center, prospective, naturalistic, observational cohort study. Compr Psychiatry 2019;88:29-38.

8 Lee K, Lee D, Hong HJ. Text mining analysis of teachers' reports on student suicide in South Korea. Eur Child Adolesc Psychiatry 2020;29:453-465.

9 Jung S, Lee D, Park S, et al. Subtypes of suicidal ideation in Korean adolescents: a multilevel latent profile analysis. Aust $N Z J$ Psychiatry 2019;53:158-67.

10 Kwak CW, Ickovics JR. Adolescent suicide in South Korea: risk factors and proposed multi-dimensional solution. Asian $J$ Psychiatr 2019;43:150-3.

11 Jung S, Lee D, Park S, et al. Gender differences in Korean adolescents who died by suicide based on teacher reports. Child Adolesc Psychiatry Ment Health 2019;13:12.

12 Giusti A, Maggini M, Colaceci S. The burden of chronic diseases across Europe: what policies and programs to address diabetes? A SWOT analysis. Health Res Policy Syst 2020;18:12.

13 Kumar P, Jangid P, Sethi S. Undergraduate psychiatry in India: a SWOT analysis. Asian $J$ Psychiatr 2018;33:46-51.

14 Zhu Y, Zhong N, Su H, et al. Strengths, weaknesses, opportunities and threats (SWOT) analysis of reinitiation into methamphetamine abusers: qualitative findings from an exploration of methamphetamine abusers in Shanghai, China. Gen Psychiatr 2019;32:e100062.

15 Alteri A, Corti L, Sanchez AM, et al. Assessment of pre-implantation genetic testing for embryo aneuploidies: a SWOT analysis. Clin Genet 2019;95:479-87.

16 Costantino C, Mazzucco W, Marotta C et al. Methodological issues in a crosssectional survey on cervical cancer screening using telephone interviews in Sicily (Italy): a SWOT analysis. J Int Med Res 2019;47:5174-84.

17 Roh S, Lee S-U, Soh M, et al. Mental health services and R\&D in South Korea. Int $J$ Ment Health Syst 2016;10:45.

$18 \mathrm{Kim} \mathrm{H}$, Kwon SW, Ahn YM, et al. Implementation and outcomes of suicideprevention strategies by restricting access to lethal suicide methods in Korea. $J$ Public Health Policy 2019:40:91-102.

19 Korean Association for Suicide Protection, 2011. Available: http://suicideprevention.or. kr/new2/contents/sub0301.php [Accessed 13 Sept 2019].

20 Korea Association for Suicide Prevention. Work introduction-Livingwork suicide preventive education, 2017. Available: http://suicideprevention.or.kr/new2/ contents/sub0501.php [Accessed 26 Sept 2019].

21 Duffy A, Goodday SM, KeownStoneman C, et al. Epigenetic markers in inflammation-related genes associated with mood disorder: a cross-sectional and longitudinal study in high-risk offspring of bipolar parents. Int J Bipolar Disord 2019;7:17.

22 Choi Y-S, Shin HK, Hong D-Y, et al. Selfesteem as a moderator of the effects of happiness, depression, and hostility on suicidality among early adolescents in Korea. J Prev Med Public Health 2019;52:30-40.

23 Cha JM, Kim JE, Kim MA, et al. Five months follow-up study of school-based crisis intervention for Korean high school students who experienced a peer suicide. $J$ Korean Med Sci 2018;33:e192.

24 Hoffman GE, Bendl J, Voloudakis G et al. CommonMind Consortium provides transcriptomic and epigenomic data for schizophrenia and bipolar disorder. Sci Data 2019;6:180.

25 Schwabe I, Milaneschi Y, Gerring Z, et al. Unraveling the genetic architecture of major depressive disorder: merits and pitfalls of the approaches used in genomewide association studies. Psychol Med 2019;49:2646-56

26 Kwon H, Kim R, Roh B-R, et al. Suicide prevention program in schools: teacher's perception of benefits and barriers. J Korean Neuropsychiatr Assoc 2014;53:8-14.

27 Young Health Programme. YHP South Korea-safeTALK, 2011. Available: https:// www.younghealthprogrammeyhp.com/ programmes/korea.html [Accessed 13 Sept 2019].

28 Guest JL, Del Rio C, Sanchez T. The three steps needed to end the COVID-19 pandemic: BOLD public health leadership, rapid innovations, and courageous political will. JMIR Public Health Surveill 2020;6:e19043.

29 Murdoch D, Addidle M, Andersson H-S, et al. Politicians: please work together to minimise the spread of COVID-19. NZ Med J 2020;133:7-8.

30 Moran-Bates J. Youth suicide legislation in the 2019 session of the North 
Carolina General Assembly. N C Med J 2020;81:108-9.

31 Kirtley OJ, O'Connor RC. Suicide prevention is everyone's business: challenges and opportunities for Google. Soc Sci Med 2020;18:112691.

32 Phillips JG, Diesfeld K, Mann L. Instances of online suicide, the law and potential solutions. Psychiatr Psychol Law 2019;26:423-40.

33 Dagar A, Falcone T. High viewership of videos about teenage suicide on YouTube. $J$ Am Acad Child Adolesc Psychiatry 2020;59:1-3.

34 Liu X, Liu X, Sun J, et al. Proactive suicide prevention online (PSPO): machine identification and crisis management for Chinese social media users with suicidal thoughts and behaviors. J Med Internet Res 2019;21:e11705

35 Matsumoto T, Imamura F, Chiba Y, et al. Analgesia during self-cutting: clinical implications and the association with suicidal ideation. Psychiatry Clin Neurosci 2008;62:355-8.

36 Xing Y, Lu J, Chen S. Evaluating the effectiveness of platform screen doors for preventing Metro suicides in China. J Affect Disord 2019;253:63-8.

37 Zhang F, Cloutier PF, Yang H, et al. Nonsuicidal self-injury in Shanghai inner bound middle school students. Gen Psychiatr 2019;32:e100083.

38 Song J, Park S, Lee K, et al. Influence of area-level characteristics on the suicide rate in Korean adolescents. Psychiatry Investig 2019;16:800-7.

39 Kim ES, Chin BS, Kang CK, et al. Clinical course and outcomes of patients with severe acute respiratory syndrome coronavirus 2 infection: a preliminary report of the first 28 patients from the Korean cohort study on COVID-19. J Korean Med Sci 2020;35:e142.

40 Mamun MA, Griffiths MD. First COVID-19 suicide case in Bangladesh due to fear of COVID-19 and xenophobia: possible suicide prevention strategies. Asian J Psychiatr 2020;51:102073.

41 Monteith LL, Holliday R, Brown TL, et al. Preventing suicide in rural communities during the COVID-19 pandemic. J Rural Health 2020. doi:10.1111/jirh.12448

42 Stop the coronavirus stigma now. Nature 2020;580:165.

43 Dalton L, Rapa E, Stein A. Protecting the psychological health of children through effective communication about COVID-19. Lancet Child Adolesc Health 2020;4:346-7.

44 Zhai Y, Du X. Mental health care for international Chinese students affected by the COVID-19 outbreak. Lancet Psychiatry 2020;7:e22.

45 Kim S, Kim YJ, Peck KR, et al. School opening delay effect on transmission dynamics of coronavirus disease 2019 in Korea: based on mathematical modeling and simulation study. J Korean Med Sci 2020;35:e143.

46 Mei G, Xu W, Li L, et al. The role of campus data in representing depression among college students: exploratory research. JMIR Ment Health 2020;7:e12503.

47 Mackenzie J-M, Borrill J, Hawkins E, et al. Behaviours preceding suicides at railway and underground locations: a multimethodological qualitative approach. BMJ Open 2018;8:e021076.

48 Fletcher I, Castle M, Scarpa A, et al. An exploration of medical student attitudes towards disclosure of mental illness. Med Educ Online 2020;25:1727713.

49 Park Y, Baik SY, Kim H-S, et al. The influence of traditional culture and the interpersonal psychological theory on suicide research in Korea. Psychiatry Investig 2017;14:713-8.

50 Hampel H, Caraci F, Cuello AC, et al. A path toward precision medicine for neuroinflammatory mechanisms in Alzheimer's disease. Front Immunol 2020;11:456.

51 Habtewold TD, Islam MA, Liemburg EJ, et al. Polygenic risk score for schizophrenia was not associated with glycemic level (HbA1c) in patients with non-affective psychosis: genetic risk and outcome of psychosis (group) cohort study. $J$ Psychosom Res 2020;132:109968.

52 Liyanarachchi S, Gudmundsson

$\mathrm{J}$, Ferkingstad E, et al. Assessing thyroid cancer risk using polygenic risk scores. Proc Natl Acad Sci U S A 2020;117:5997-6002.

53 Koo BK, Joo SK, Kim D, et al. Development and validation of a scoring system, based on genetic and clinical factors, to determine risk of steatohepatitis in Asian patients with nonalcoholic fatty liver disease. Clin Gastroenterol Hepatol 2020. doi:10.1016/j. cgh.2020.02.011

54 Xie K, Zhang Y, Wen J, et al. Genetic predisposition to gestational glucose metabolism and gestational diabetes mellitus risk in a Chinese population. $J$ Diabetes 2019;11:869-77.

55 Song $\mathrm{C}$, Wang $\mathrm{M}$, Fang $\mathrm{H}$, et al. Effects of variants of 50 genes on diabetes risk among the Chinese population born in the early 1960s. J Diabetes 2019;11:857-68.

56 Oram RA, Patel K, Hill A, et al. A type 1 diabetes genetic risk score can aid discrimination between type 1 and type 2 diabetes in young adults. Diabetes Care 2016;39:337-44.

57 Chen Y, Zhou T, Sun D, et al. Distinct genetic subtypes of adiposity and glycemic changes in response to weight-loss diet intervention: the pounds lost trial. Eur $J$ Nutr 2020. doi:10.1007/s00394-02002244-x

58 Ruderfer DM, Walsh CG, Aguirre MW, et al. Significant shared heritability underlies suicide attempt and clinically predicted probability of attempting suicide. Mol Psychiatry 2019. doi:10.1038/s41380-0180326-8

59 Grimmond J, Kornhaber R, Visentin D, et al. A qualitative systematic review of experiences and perceptions of youth suicide. PLoS One 2019;14:e0217568.

60 Mullins N, Bigdeli TB, Børglum AD, et al. GWAS of suicide attempt in psychiatric disorders and association with major depression polygenic risk scores. Am J Psychiatry 2019;176:651-60.

61 Erlangsen A, Appadurai V, Wang Y, et al. Genetics of suicide attempts in individuals with and without mental disorders: a population-based genome-wide association study. Mol Psychiatry 2018. doi:10.1038/ s41380-018-0218-y

62 Brundin L, Bryleva EY, Thirtamara Rajamani K. Role of inflammation in suicide: from mechanisms to treatment. Neuropsychopharmacology 2017;42:271-83.

63 Sudol K, Mann JJ. Biomarkers of suicide attempt behavior: towards a biological model of risk. Curr Psychiatry Rep 2017:19:31.

64 Elgendy R, Deschênes SS, Burns RJ, et al. Alcohol consumption, depressive symptoms, and the incidence of diabetesrelated complications. J Diabetes 2019;11:14-22.

$65 \mathrm{He} \mathrm{J}$, Li S, Liu F, et al. Glycemic control is related to cognitive dysfunction in Chinese children with type 1 diabetes mellitus. $J$ Diabetes 2018:10:948-57.

66 Morone J. Systematic review of sociodemographic representation and cultural responsiveness in psychosocial and behavioral interventions with adolescents with type 1 diabetes. $J$ Diabetes 2019;11:582-92.

67 Plans L, Barrot C, Nieto E, et al. Association between completed suicide and bipolar disorder: a systematic review of the literature. J Affect Disord 2019;242:111-22.

68 Mörch C-M, Côté L-P, Corthésy-Blondin $\mathrm{L}$, et al. The Darknet and suicide. J Affect Disord 2018;241:127-32.

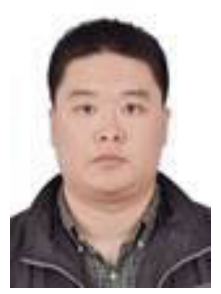

Jiacheng Liu is in a master's program on public health in Melbourne School of Population E Global Health, Division of Medicine, Dentistry and Health Sciences, The University of Melbourne from 2019 to 2021. His research interests include global epidemiology, prevention and treatment of psychological disorders and other non-communicable diseases, with a special focus on the area of suicide prevention strategies aimed at improving the public awareness and knowledge about mental health problems and increasing the standard of basic and clinical research on psychiatric disorders. 